\title{
openheart Prognostic significance of repeated brain natriuretic peptide measurements after percutaneous transluminal septal myocardial ablation in patients with drug-refractory hypertrophic obstructive cardiomyopathy
}

\author{
Keitaro Akita, ${ }^{1,2}$ Hikaru Tsuruta, ${ }^{2}$ Shinsuke Yuasa, ${ }^{2}$ Mitsushige Murata, ${ }^{2}$ \\ Keiichi Fukuda, ${ }^{2}$ Yuichiro Maekawa ${ }^{1}$
}

To cite: Akita K, Tsuruta $\mathrm{H}$, Yuasa S, et al. Prognostic significance of repeated brain natriuretic peptide measurements after percutaneous transluminal septal myocardial ablation in patients with drug-refractory hypertrophic obstructive cardiomyopathy. Open Heart 2018;5:e000786. doi:10.1136/ openhrt-2018-000786

Received 26 January 2018 Revised 15 April 2018 Accepted 24 April 2018

\section{Check for updates}

IInternal Medicine III, Hamamatsu University School of Medicine, Hamamatsu, Shizuoka, Japan ${ }^{2}$ Department of Cardiology, Keio University School of Medicine, Tokyo, Japan

Correspondence to Dr Yuichiro Maekawa; ymaekawa@a5.keio.jp

\section{ABSTRACT}

Objectives To evaluate whether repeated brain natriuretic peptide (BNP) measurements after percutaneous transluminal septal myocardial ablation (PTSMA) provide prognostic information regarding the response to PTSMA in patients with drug-refractory hypertrophic obstructive cardiomyopathy (HOCM).

Background Plasma BNP levels are associated with clinical outcomes in patients with HOCM. However, the prognostic value of plasma BNP level changes before and after PTSMA remains unclear.

Methods We measured the plasma BNP levels serially before and after PTSMA, and evaluated the relationship between the changes in plasma BNP levels and clinical improvement in 47 patients. The patients were assigned to two groups based on the reduction in the New York Heart Association class $\geq 1$ (good responder) or $<1$ (poor responder) before and after PTSMA. The Kansas City Cardiomyopathy Questionnaire (KCCQ) was used to measure health status.

Results The plasma BNP levels gradually decreased after PTSMA, although the levels plateaued 3 months until 12 months after PTSMA. Although the plasma BNP levels and resting left ventricular outflow tract peak pressure gradient before PTSMA were comparable between the groups, the ratio of the BNP levels before and after PTSMA in the good responder group was significantly lower than that in the poor responder group ( 0.43 (range, $0.24-0.68$ ) vs 0.78 (range, $0.62-0.93), p=0.002$ ). The $K C C Q$ score changes in the good responder group were significantly higher than those in the poor responder group.

Conclusions The plasma BNP level ratio was associated with long-term clinical improvement of heart failure after PTSMA for drug-refractory HOCM.

\section{INTRODUCTION}

Brain natriuretic peptide (BNP) is mainly secreted from the left ventricle, and elevated blood BNP levels are caused by left ventricular (LV) wall stress. Plasma BNP levels

\section{Key questions}

What is already known about this subject?

- Brain natriuretic peptide (BNP) is expressed in the ventricular myocytes in patients with hypertrophic cardiomyopathy, with particularly high levels observed in patients with left ventricular outflow tract obstruction and diastolic dysfunction.

- It is unclear whether BNP level is useful for evaluating the clinical improvement of heart failure after percutaneous transluminal septal myocardial ablation (PTSMA).

What does this study add?

- This is the first study to assess the time course of the plasma BNP levels after PTSMA up to 12 months, and the ratio of plasma BNP levels obtained from repeated measurements of the BNP level as compared with the single measurement of BNP, was associated with long-term clinical improvement of heart failure after PTSMA for drugrefractory hypertrophic obstructive cardiomyopathy.

How might this impact on clinical practice?

- The ratio of plasma BNP levels before and after PTSMA may provide better information for predicting the clinical outcomes, based on the individual haemodynamics.

have been demonstrated to be significantly associated with the clinical status of congestive heart failure, acute coronary syndrome, hypertrophic cardiomyopathy (HCM) and valvular disease, and also provide prognostic information regarding the response to pharmacological and interventional therapy. ${ }^{1-6}$ Previous studies showed that BNP is expressed in the ventricular myocytes in patients with HCM, with particularly high levels observed in patients with left ventricular outflow tract 
(LVOT) obstruction and diastolic dysfunction. ${ }^{7-9}$ Percutaneous transluminal septal myocardial ablation (PTSMA) is one of the septal reduction therapies that relieve symptoms related to heart failure in patients with drug-refractory hypertrophic obstructive cardiomyopathy (HOCM) ${ }^{10-12}$ A previous study showed that the in-hospital mortality after PTSMA was low, and that the haemodynamic and symptomatic effects were sustained in the long-term. ${ }^{13}$ Patients with HOCM tend to have high levels of BNP and a single measurement of the BNP level may provide prognostic information. ${ }^{6}$ However, the Valsartan Heart Failure Therapy trial showed that information obtained from repeated measurements of the BNP level was superior to the prognostic value of a single assessment ${ }^{14} 15$; nevertheless, it is unclear whether the serial measurement of BNP levels before and after PTSMA is useful for evaluating the clinical improvement of heart failure after PTSMA. Therefore, in the present study, we aimed to evaluate whether the repeated measurements of plasma BNP levels can provide prognostic information regarding the response to PTSMA in patients with drug-refractory HOCM.

\section{METHODS}

\section{Ethics statement}

All participants provided written informed consent prior to study participation.

\section{Study design}

We included 54 consecutive patients with drug-refractory HOCM that were treated with PTSMA, and measured the plasma BNP levels between November 2011 and January 2016 at the Keio University Hospital. Of these patients, five were excluded because their plasma BNP levels could not be followed up until 1 year after PTSMA and two were excluded because they had the mid-ventricular obstruction type of HOCM. Thus, 47 patients were included in the final analysis (figure 1). All the patients underwent comprehensive clinical, echocardiographic and coronary angiographic evaluations at the Keio University Hospital.

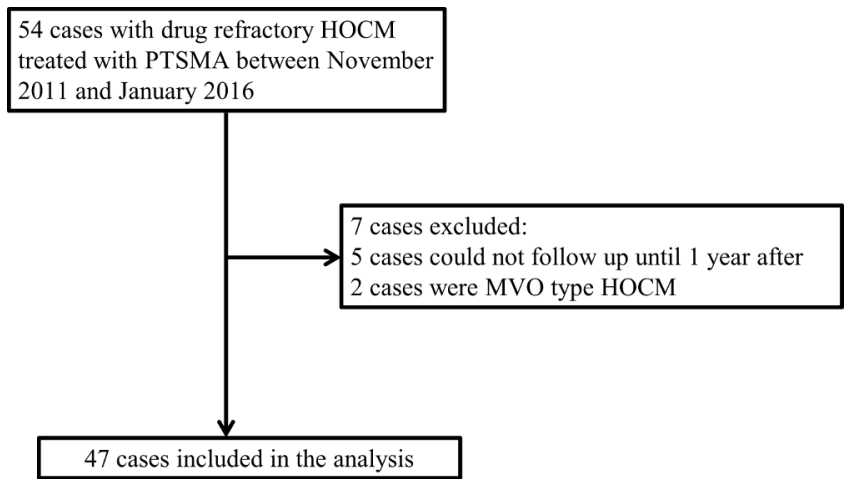

Figure 1 Clinical characteristics of the patients included and excluded from the study. BNP, brain natriuretic peptide; HOCM, hypertrophic obstructive cardiomyopathy; MVO, midventricular obstruction; PTSMA, percutaneous transluminal septal myocardial ablation.
Subjects underwent serial measurements of plasma BNP levels before and after PTSMA at 1, 3, 6, 9 and 12 months, along with an evaluation of the clinical outcomes. In the present study, the plasma BNP level before PTSMA was defined as the average of the last and second last values recorded before the session, both of which were measured within 3 months before the session. The ratio of plasma BNP levels before and after PTSMA was defined as the division of the plasma BNP level after PTSMA by the level before PTSMA, according to the time course of the plasma BNP levels during the follow-up period. Patients were divided into two groups based on whether they exhibited a reduction in the New York Heart Association (NYHA) class $\geq 1$ (good responder) or $<1$ (poor responder) characteristics before and after PTSMA. The changes in the NYHA class before and after PTSMA were evaluated at 12 months to determine whether patients were good responders or poor responders.

\section{PTSMA indications and procedure}

The indication for PTSMA included the presence of severe drug-refractory symptoms (NYHA class III/IV, Canadian Cardiovascular Society class III/IV or NYHA class II symptoms with recurrent exercise-induced syncope) in combination with LVOT pressure gradients $(\mathrm{PG}) \geq 30 \mathrm{~mm}$ $\mathrm{Hg}$ at rest or $\geq 50 \mathrm{~mm} \mathrm{Hg}$ during provocation by the Valsalva manoeuvre or exercise. The procedure was offered to patients referred to our HOCM clinic with refractory symptoms despite being administered maximally tolerated medical therapy (beta-blockers, calcium channel blockers and cibenzoline or disopyramide), and those who were not candidates for surgical myectomy due to either the presence of comorbidities or patient preference. PTSMA was performed according to a previously reported protocol. ${ }^{11} 1216$ In brief, all patients without a previously implanted permanent pacemaker had a prophylactic temporary pacemaker inserted before the procedure. A 6 Fr femoral arterial sheath was inserted for the guide catheter system and a $5 \mathrm{Fr}$ radial sheath was inserted for pigtail catheter placement into the LV cavity. Continuous invasive peak-to-peak gradients were measured across the LVOT by comparing the peak LV and aortic pressure. A septal perforating artery supplying the obstructing part of the septum was identified on coronary angiography and cardiac multidetector CT, and was chosen as the target vessel. After the occlusion of the septal target branch by an over-the-wire balloon, the perfused septal area was visualised by echocardiography, following the injection of $1-2 \mathrm{~mL}$ of echocardiography contrast medium. After all the patients received morphine chloride intravenously for pain control, absolute ethanol was slowly injected into the target vessel through a balloon catheter. The balloon was deflated and removed after $10 \mathrm{~min}$. The occlusion of the target vessel was verified angiographically at the end of the procedure. All the patients were monitored in the coronary care unit after the procedure for at least 48 hours. Creatine phosphokinase (CK) levels were monitored at 8 hours interval for the first 24 hours, and daily thereafter for 2 days. All the patients 
were followed up at least every 2 months after the PTSMA procedure at our clinic.

\section{Echocardiography}

Echocardiograms were performed at the Keio University Hospital. Conventional echocardiographic analyses, including two-dimensional and Doppler imaging, were performed by technicians blinded to the patients' clinical information.

\section{Clinical demographic data}

Patient demographic data included the prevalence of concomitant diseases, history of invasive therapies and procedural data. The Kansas City Cardiomyopathy Questionnaire (KCCQ) is a 23-item, self-administered questionnaire that quantifies physical function, symptoms, social function, self-efficacy and quality of life for patients with heart failure. We used the KCCQ-12, which is a shortened version of the instrument that includes the psychometric properties of the full KCCQ and helps measure health status in patients with heart failure. ${ }^{17}$ The validity and reliability as well as the responsiveness to clinical changes of this questionnaire have been previously established. The range for this scale is $0-100$; higher scores reflect better health status (symptoms, function and quality of life). ${ }^{18-21}$ We investigated all-cause mortality as well as new admission for heart failure, new requirement for invasive therapies including myectomy, repeated-PTSMA, permanent pacemaker implantation, stroke and cardiac death including sudden death during the short-term and longterm.

\section{Statistical analyses}

Continuous variables are expressed as mean $\pm \mathrm{SD}$ unless otherwise specified. BNP is not normally distributed and is reported as median and lower upper quartile. Categorical variables are expressed as absolute values and percentages. The relationships between the ratios of BNP and of resting LVOT peak PG and the reduction in NYHA class, were estimated using Spearman's rank correlation coefficients. The relationship between the ratio of BNP and the ratio of resting LVOT peak PG was also estimated using Spearman's rank correlation coefficients. Receiver operating characteristic analysis was performed to assess the optimal cut-off values for the ratio of BNP levels before and after PTSMA according to the reduction in NYHA class $\geq 1$. All the $p$ values were two-sided. Results were considered statistically significant at a $\mathrm{p}$ value $<0.05$. All analyses were performed using IBM SPSS Statistics V.23 (IBM, Armonk, New York, USA).

\section{RESULTS}

\section{Baseline characteristics}

A total of 47 patients were included in the final analysis (figure 1). The baseline characteristics of the participants are listed in table 1 . The mean age was $68 \pm 12$ years, and $46.8 \%$ of all patients were categorised as NYHA class III

\section{Table 1 Baseline characteristics}

\begin{tabular}{|c|c|}
\hline & $\mathrm{n}=47$ \\
\hline Age, years & $68 \pm 12$ \\
\hline $\mathrm{BMI}\left(\mathrm{kg} / \mathrm{m}^{2}\right)$ & $22.9 \pm 4.2$ \\
\hline NYHA class $\geq 3, \mathrm{n}(\%)$ & $22(46.8)$ \\
\hline KCCQ score & $56.0 \pm 21.3$ \\
\hline Male, n (\%) & $16(34.0)$ \\
\hline Syncope, n (\%) & $12(25.5)$ \\
\hline Hypertension, n (\%) & $29(61.7)$ \\
\hline Diabetes, n (\%) & $2(4.3)$ \\
\hline Dyslipidemia, n (\%) & $27(57.4)$ \\
\hline Smoking, n (\%) & $4(8.5)$ \\
\hline Stroke n (\%) & $4(8.5)$ \\
\hline Family history of sudden death, $\mathrm{n}(\%)$ & $5(10.6)$ \\
\hline Family history of HCM, n (\%) & $7(14.9)$ \\
\hline Atrial fibrillation, $\mathrm{n}(\%)$ & $8(17.0)$ \\
\hline COPD, n (\%) & $2(4.3)$ \\
\hline Coronary artery disease, n (\%) & $4(8.5)$ \\
\hline Peripheral artery disease, $\mathrm{n}(\%)$ & $0(0.0)$ \\
\hline Malignancy, n (\%) & $8(17.0)$ \\
\hline ICD/pacemaker implantation, n (\%) & $6(12.8)$ \\
\hline \multicolumn{2}{|l|}{ Medication, n (\%) } \\
\hline Sodium channel blocker & $33(70.2)$ \\
\hline Beta-blocker & $45(95.7)$ \\
\hline Calcium channel blocker & $20(42.6)$ \\
\hline Diuretics & $9(19.1)$ \\
\hline Anticoagulation & $10(21.3)$ \\
\hline \multicolumn{2}{|l|}{ Laboratory data } \\
\hline $\mathrm{BNP}(\mathrm{pg} / \mathrm{mL})$ & $389.9(156.0-802.4)$ \\
\hline \multicolumn{2}{|l|}{ Echocardiographic variables } \\
\hline LVEDD (mm) & $43.2 \pm 4.7$ \\
\hline LVESD (mm) & $24.5 \pm 3.2$ \\
\hline IVST (mm) & $20.9 \pm 3.0$ \\
\hline LAD (mm) & $44.6 \pm 8.5$ \\
\hline E/e' (lateral) & $17.1 \pm 9.1$ \\
\hline Moderate or severe MR, n (\%) & $27(57.0)$ \\
\hline Resting peak LVOT PG (mm Hg) & $97.6 \pm 37.1$ \\
\hline $\begin{array}{l}\text { Preprocedural resting peak } \\
\text { LVOT PG }(\mathrm{mm} \mathrm{Hg})\end{array}$ & $74.6 \pm 47.0$ \\
\hline
\end{tabular}

Data are expressed as mean \pm SD or median (quartiles), and number (\%).

$\mathrm{BMI}$, body mass index; BNP, brain natriuretic peptide; COPD, chronic obstructive pulmonary disease; $\mathrm{HCM}$, hypertrophic cardiomyopathy; ICD, implantable cardioverter defibrillator; IVST, intraventricular septal thickness; KCCQ, The Kansas City Cardiomyopathy Questionnaire; LAD, left atrial diameter; LVEDD, left ventricular end-diastolic diameter; LVEDP, left ventricular end-diastolic pressure.; LVESD, left ventricular end-systolic diameter; LVOT, left ventricular outflow tract; MR, mitral regurgitation; NYHA, New York Heart Association; PG, pressure gradient; PTSMA, percutaneous transluminal septal myocardial ablation. 
Table 2 Details of the procedure and short-term and long-term outcomes in good and poor responders

\begin{tabular}{lllll}
\hline & $\begin{array}{l}\text { All patients } \\
(\mathbf{n}=\mathbf{4 7})\end{array}$ & $\begin{array}{l}\text { Good responders } \\
(\mathbf{n = 2 9 )}\end{array}$ & $\begin{array}{l}\text { Poor responders } \\
(\mathbf{n}=\mathbf{1 8})\end{array}$ & P values \\
\hline Procedure & & & & \\
\hline Number of injected septal arteries & $2.3 \pm 1.0$ & $2.5 \pm 1.0$ & $1.9 \pm 0.9$ & 0.08 \\
\hline Volume of ethanol (mL) & $3.7 \pm 1.5$ & $4.0 \pm 1.5$ & $3.1 \pm 1.2$ & 0.028 \\
\hline Max CK (U/L) & $1450.4 \pm 667.6$ & $1611.4 \pm 624.0$ & $1191.0 \pm 670.2$ & 0.034 \\
\hline Postprocedural resting peak LVOT PG (mm Hg) & $20.7 \pm 31.5$ & $22.8 \pm 33.9$ & $17.3 \pm 27.9$ & 0.57 \\
\hline Outcomes & & & & \\
\hline In-hospital, $n$ (\%) & & & & 1.00 \\
\hline Death & $0(0.0)$ & $0(0.0)$ & $0(0.0)$ & 0.26 \\
\hline VT/NF & $2(4.3)$ & $2(6.9)$ & $0(0.0)$ & 0.79 \\
\hline Complete AV block & $6(12.8)$ & $4(13.8)$ & $2(11.1)$ & 0.20 \\
\hline New ICD/pacemaker implantation & $3(6.4)$ & $3(11.1)$ & $0(0.0)$ & 1.00 \\
\hline Stroke & $0(0.0)$ & $0(0.0)$ & $0(0.0)$ & 1.00 \\
\hline Cardiac tamponade & $0(0.0)$ & $0(0.0)$ & $0(0.0)$ & 0.43 \\
\hline New atrial fibrillation & $1(2.1)$ & $1(3.4)$ & $0(0.0)$ & \\
\hline 12 months, $n$ (\%) & & & & 1.00 \\
\hline Death & $0(0.0)$ & $0(0.0)$ & $0(0.0)$ & 0.73 \\
\hline VT/NF & $2(4.3)$ & $1(3.4)$ & $1(5.6)$ & 0.17 \\
\hline New ICD/pacemaker implantation & $1(2.1)$ & $0(0.0)$ & $1(5.6)$ & 1.00 \\
\hline Stroke & $0(0.0)$ & $0(0.0)$ & $0(0.0)$ & 1.00 \\
\hline Repeated PTSMA & $0(0.0)$ & $0(0.0)$ & $0(0.0)$ & 1.00 \\
\hline HF admission & $0(0.0)$ & $0(0.0)$ & $0(0.0)$ & \\
\hline
\end{tabular}

Data are expressed as mean \pm SD and number (\%). $\mathrm{P}$ value for comparison of good responders vs poor responders.

AV, atrioventricular; CK, creatine phosphokinase; HF, heart failure; ICD, implantable cardioverter defibrillator; LVOT, left ventricular outflow tract; PG, pressure gradient; PTSMA, percutaneous transluminal septal myocardial ablation; VT/VF, ventricular tachycardia/ventricular fibrillation.

or IV. The median plasma BNP level was $389.9 \mathrm{pg} / \mathrm{mL}$ (range, $156.0-802.4 \mathrm{pg} / \mathrm{mL}$ ).

\section{Procedure and outcomes between good and poor responders}

The details of the procedure and short-term and longterm outcomes are listed in table 2. Although volume of ethanol and Max CK values were significantly higher in the good responder group than in the poor responder group, there were no in-hospital deaths or deaths within 12 months of the procedure in the two groups. Although two patients developed ventricular tachycardia or ventricular fibrillation, and one patient required implantable cardioverter defibrillator implantation, none of the patients required repeated PTSMA or readmission for heart failure during the follow-up period.

\section{Time course of plasma BNP levels after PTSMA and differences in various parameters after PTSMA between good and poor responders}

The plasma BNP levels gradually decreased after PTSMA, but the levels plateaued at 3 months after PTSMA and continued until 12 months (figure 2). Therefore, we compared the plasma BNP levels at 3 months, and the ratio of plasma BNP levels between the good and poor responders. Although the plasma BNP levels following
PTSMA at 3 months were comparable between the groups, the ratio of plasma BNP levels before and after PTSMA in the good responder group was significantly lower than that in the poor responder group $(0.43$ (range, 0.24-0.68) vs 0.78 (range, 0.62-0.93), $\mathrm{p}=0.002$ ). This trend continued until 12 months after PTSMA

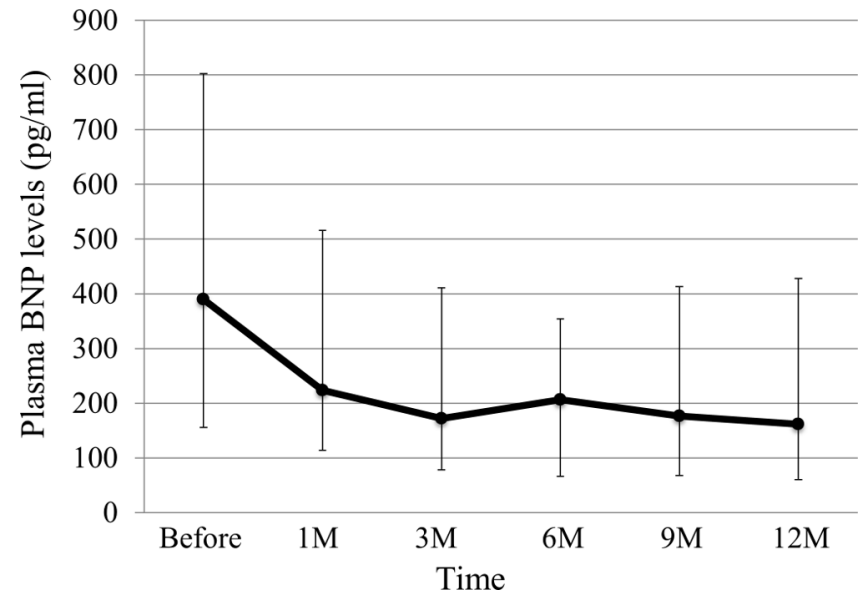

Figure 2 Time course of median brain natriuretic peptide (BNP) levels during follow-up period. BNP levels at each time point are expressed as median and the lower-upper quartile. 


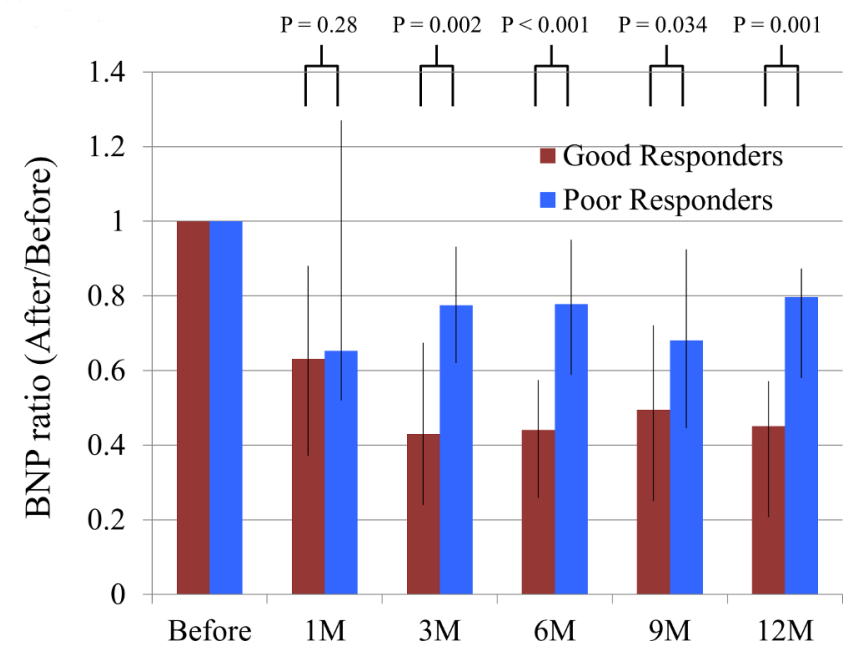

Figure 3 The change in the ratio of plasma brain natriuretic peptide (BNP) level before and after percutaneous transluminal septal myocardial ablation, between the good and poor responder groups. The ratio of plasma BNP level at each time point are expressed as median and the lowerupper quartile.

(figure 3). Moreover, the ratio of $\mathrm{BNP}$, before and 3 months after PTSMA, significantly correlated with NYHA class reduction (Spearman's $\rho=-0.36, p=0.01$ ). The resting LVOT peak PG measured by echocardiography, the proportion of moderate or severe mitral regurgitation (MR) and the left atrial diameter following PTSMA at 12 months were comparable between both the groups. The ratios of resting LVOT peak PG before and 6 and 12 months after PTSMA, were significantly correlated with NYHA class reduction (Spearman's $\rho=-0.407, p=0.009$, $\rho=-0.409, p=0.023$, respectively). However, the ratio of BNP before and 3 months after PTSMA was not correlated with the ratio of resting LVOT peak PG before and 6 and 12 months after PTSMA (Spearman's $\rho=0.304$, $p=0.056, \rho=0.009, p=0.96$, respectively). The NYHA class following PTSMA at 12 months was significantly lower in the good responder group than in the poor responder group (table 3 ).

\section{Cut-off value of the ratio of BNP related to good response of NYHA class reduction after PTSMA}

An area under the receiver operating characteristic curve value of 0.769 for the $\mathrm{BNP}$ ratio, and a $\mathrm{BNP}$ ratio of 0.66 , was related to a reduction in NYHA class $\geq 1$ with a sensitivity of $78 \%$ and specificity of $76 \%$. When we divided the patients into two groups according to the cut-off value of 0.66 for the $\mathrm{BNP}$ ratio, the proportion of patients in the good responder group was significantly greater in the ratio of $\mathrm{BNP}<0.66$ group compared with the ratio of $\mathrm{BNP} \geq 0.66$ group $(75.9 \%$ vs $22.2 \%, \mathrm{p}<0.001)$.

Table 3 Difference of various parameters post-PTSMA between good and poor responders

\begin{tabular}{|c|c|c|c|}
\hline & $\begin{array}{l}\text { Good responders } \\
(n=29)\end{array}$ & $\begin{array}{l}\text { Poor responders } \\
(n=18)\end{array}$ & P values \\
\hline \multicolumn{4}{|l|}{ Laboratory data } \\
\hline BNP before PTSMA (pg/mL) & $414.2(161.6-788.6)$ & $326.8(104.0-857.3)$ & 0.71 \\
\hline BNP 3 months after PTSMA (pg/mL) & $144.2(71.6-315.9)$ & $225.0(92.6-624.8)$ & 0.26 \\
\hline Ratio of BNP (after 3 months/before) & $0.43(0.24-0.68)$ & $0.78(0.62-0.93)$ & 0.002 \\
\hline \multicolumn{4}{|l|}{ Echocardiographic variables before PTSMA } \\
\hline LVEDD (mm) & $43.0 \pm 3.9$ & $43.8 \pm 5.8$ & 0.58 \\
\hline LVESD (mm) & $24.3 \pm 2.9$ & $24.8 \pm 3.7$ & 0.62 \\
\hline IVST (mm) & $20.9 \pm 2.7$ & $20.9 \pm 3.5$ & 0.99 \\
\hline $\operatorname{LAD}(\mathrm{mm})$ & $43.0 \pm 9.0$ & $47.1 \pm 7.1$ & 0.10 \\
\hline E/e' (lateral) & $17.2 \pm 9.9$ & $16.9 \pm 7.9$ & 0.93 \\
\hline Moderate or severe MR, $\mathrm{n}(\%)$ & $15(51.7)$ & $12(66.7)$ & 0.37 \\
\hline Resting peak LVOT PG (mm Hg) & $94.4 \pm 38.9$ & $102.6 \pm 34.4$ & 0.47 \\
\hline \multicolumn{4}{|c|}{ Echocardiographic variables at 12 months after PTSMA } \\
\hline $\mathrm{LAD}(\mathrm{mm})$ & $39.8 \pm 8.6$ & $44.3 \pm 8.8$ & 0.095 \\
\hline E/e' (lateral) & $12.7 \pm 6.1$ & $15.8 \pm 7.2$ & 0.14 \\
\hline Moderate or severe MR, $\mathrm{n}(\%)$ & $2(6.9)$ & $3(16.7)$ & 0.31 \\
\hline Resting peak LVOT PG (mm Hg) & $27.4 \pm 26.6$ & $48.0 \pm 36.7$ & 0.08 \\
\hline NYHA before PTSMA & $2.9 \pm 0.4$ & $2.6 \pm 0.2$ & 0.001 \\
\hline NYHA at 12 months after PTSMA & $1.5 \pm 0.5$ & $2.1 \pm 0.2$ & $<0.001$ \\
\hline
\end{tabular}

Data are expressed as mean \pm SD or median (quartiles), and number (\%).

BNP, brain natriuretic peptide; IVST, intraventricular septal thickness; LAD, left atrial diameter; LVEDD, left ventricular end-diastolic diameter; LVESD, left ventricular end-systolic diameter; LVOT, left ventricular outflow tract; MR, mitral regurgitation; NYHA, New York Heart Association; PTSMA, percutaneous transluminal septal myocardial ablation; PG, pressure gradient. 


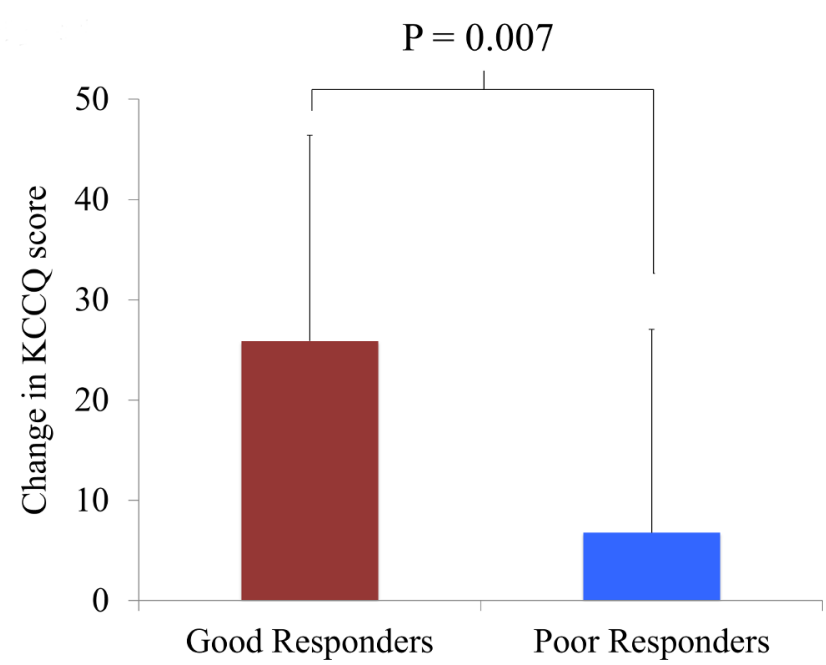

Figure 4 Change in the Kansas City Cardiomyopathy Questionnaire (KCCQ) score before and after percutaneous transluminal septal myocardial ablation between the good and poor responder groups. Change in the KCCQ score are expressed as mean \pm SD.

\section{Relationship between the ratio of BNP and change in the KCCQ score before and after PTSMA}

Change in the KCCQ score before and after PTSMA was significantly higher in the good responder group than in the poor responder group (figure 4).

\section{DISCUSSION}

In the present study, we focused on the prognostic significance of the serial measurements of BNP before and after PTSMA, as well as the association between the ratio of BNP and clinical improvement after PTSMA for drug-refractory HOCM. To our knowledge, this is the first study to assess the time course of the plasma BNP levels after PTSMA up to 12 months, and the ratio of plasma BNP levels was associated with long-term clinical improvement of heart failure after PTSMA for drug-refractory HOCM.

A previous study showed that the plasma BNP concentration reflects the intraventricular PG and LV diastolic dysfunction in patients with $\mathrm{HCM}^{7}$ Although PTSMA is an established treatment for resolving heart failure-associated symptoms in patients with drug-refractory HOCM, ${ }^{1322} 23$ factors that can predict long-term response to PTSMA have indicated inconclusive findings. In patients who underwent PTSMA, baseline comorbidities and age were found to be predictors of long-term symptomatic outcome and survival. ${ }^{13}$ However, the background of the patients was not uniform at the individual level in the studies. The finding of the present study that the ratio of plasma BNP levels before and after PTSMA was closely associated with clinical improvement in heart failure did not depend on the patient background, and may hence be more readily applied in clinical settings. Furthermore, even though the plasma BNP levels may vary according to patient background and haemodynamics, ${ }^{2}$ the ratio may offer superior information regarding the effect of PTSMA on haemodynamics before and after PTSMA.
In support of our hypothesis, the BNP levels before and after PTSMA at 3 months also did not predict the degree of improvement in heart failure-associated symptoms after PTSMA, whereas the ratio of BNP before and after PTSMA was closely associated with clinical improvement in heart failure.

The findings of the serial measurements of BNP levels in the present study were useful in evaluating the response to PTSMA, and were consistent with findings of previous studies of patients with heart failure. ${ }^{24} 25 \mathrm{~A}$ previous study demonstrated that the absolute natriuretic peptide N-terminal (NT)-proBNP levels are not necessarily correlated with the heart failure clinical disease severity score that reflects the clinical status; however, changes in NT-proBNP levels during the follow-up period are correlated with the changes in the clinical status. ${ }^{24}$ In the ProBNP Outpatient Tailored Chronic Heart Failure Therapy study, a substantial reduction in the NT-proBNP levels was accompanied by a significant reduction in a composite outcome, including worsening heart failure, hospitalisation for heart failure and cardiovascular death, whereas improved outcomes were accompanied by significantly better patient-reported quality of life. ${ }^{25} \mathrm{As}$ indicated in the present study and previous studies, serial measurements of the BNP or NT-proBNP levels can offer superior prognostic information as compared with that presented by the single measurement of either parameter. $^{1415}$

Rigopoulos and Seggewiss suggested that the progression of histological changes affects the haemodynamic response after PTSMA, which occurs in three separate phases: perioperative, early postoperative and late postoperative. The first phase is characterised by akinesia of the ablated septum with significant LVOT gradient decrease. In the following few months, the thinning of the ablated septum will cause a further decrease in the LVOT gradient and concomitant MR. ${ }^{26}$ Consistent with the above-mentioned histological changes after PTSMA, in the present study, the plasma BNP levels 1 month after PTSMA remained high, even though the levels subsequently decreased. These decreasing plasma BNP levels then plateaued at 3 months after PTSMA. Hence, knowledge of the time course of BNP levels after PTSMA is important. Although the importance of the serial measurements of BNP before and after PTSMA was showed, our study also confirmed that a significant decrease in LVOT peak PG was associated with improvement of heart failure symptoms after PTSMA, as a previous study demonstrated. ${ }^{10}$ If a patient exhibits an insufficient decrease in the BNP levels at 3 months after PTSMA, physicians should consider an assessment of the clinical status, and lifestyle adherence, or the need for further invasive therapy, including repeated PTSMA.

Previous studies have suggested that the KCCQ summary scores are roughly correlated with the NYHA functional class. The KCCQ has undergone extensive validation and has been shown to independently predict mortality and health-related quality of life in heart failure 
populations. Consistent with previous reports, ${ }^{25} 2728$ a significant change in the KCCQ score before and after PTSMA was observed in the good responder group in the present study, although no such change was observed in the poor responder group.

Several registries have demonstrated that PTSMA could improve long-term prognosis. ${ }^{13} 222930$ However, satisfactory results were not observed in all patients who underwent PTSMA. The LVOT PG on echocardiographic analysis is not always related to heart failure symptoms in HOCM, as the symptoms may be associated with LV obstruction and with the diastolic function, coexistence of atrial fibrillation and degree of MR. The ratio of plasma BNP levels before and after PTSMA may provide better information for predicting the clinical outcomes, based on the individual haemodynamics.

\section{Study limitations}

Our study population was of limited size, although truly drug-refractory HOCM patients are relatively uncommon. However, serial measurements of the BNP levels over 12 months were performed, and the PTSMA technique was consistent among these patients. A previous report showed that a consistent PTSMA technique was important and was associated with superior outcomes with alcohol septal ablation. ${ }^{31}$ Therefore, our study used a uniform study platform, thus making it possible to collect reliable data and reducing the limitations of a limited sample size. The present results may not be generalisable to the global HOCM population, as the patients were treated at a hospital with extensive experience in treating HOCM. In addition, this study showed selection bias, as we selected patients with HOCM who were suitable for PTSMA. A larger study is needed to elucidate the profound relationship between the ratio of BNP and heart failure symptoms before and after PTSMA. Our findings might provide a more careful and convenient follow-up method after PTSMA and act as a foundation for future large cohort studies focused on the relationship between the BNP ratio and septal reduction therapy.

\section{CONCLUSIONS}

To our knowledge, this is the first study to show the time course of plasma BNP levels after PTSMA until 12 months, and the ratio of plasma BNP levels was associated with long-term clinical improvement of heart failure after PTSMA for drug-refractory HOCM.

Contributors KA, HT, SY, MM, KF and YM conceived and designed the study. YM and $K A$ were responsible for analysing the data and writing the manuscript.

Funding The authors have not declared a specific grant for this research from any funding agency in the public, commercial or not-for-profit sectors.

Competing interests None declared.

Patient consent Obtained.

Ethics approval This study was approved by the institutional review board at Keio University and was conducted in accordance with the guidelines of the Declaration of Helsinki.

Provenance and peer review Not commissioned; externally peer reviewed.
Open Access This is an Open Access article distributed in accordance with the Creative Commons Attribution Non Commercial (CC BY-NC 4.0) license, which permits others to distribute, remix, adapt, build upon this work non-commercially, and license their derivative works on different terms, provided the original work is properly cited and the use is non-commercial. See: http://creativecommons.org/ licenses/by-nc/4.0/

(C) Article author(s) (or their employer(s) unless otherwise stated in the text of the article) 2018. All rights reserved. No commercial use is permitted unless otherwise expressly granted.

\section{REFERENCES}

1. Richards AM, Nicholls MG, Yandle TG, et al. Plasma N-terminal probrain natriuretic peptide and adrenomedullin: new neurohormonal predictors of left ventricular function and prognosis after myocardial infarction. Circulation 1998;97:1921-9.

2. Maron BJ, Tholakanahalli VN, Zenovich AG, et al. Usefulness of B-type natriuretic peptide assay in the assessment of symptomatic state in hypertrophic cardiomyopathy. Circulation 2004;109:984-9.

3. Troughton RW, Prior DL, Pereira JJ, et al. Plasma B-type natriuretic peptide levels in systolic heart failure: importance of left ventricular diastolic function and right ventricular systolic function. J Am Coll Cardiol 2004;43:416-22.

4. Lim P, Monin JL, Monchi M, et al. Predictors of outcome in patients with severe aortic stenosis and normal left ventricular function: role of B-type natriuretic peptide. Eur Heart J 2004;25:2048-53.

5. Maekawa Y, Anzai T, Yoshikawa T, et al. Prognostic significance of peripheral monocytosis after reperfused acute myocardial infarction:a possible role for left ventricular remodeling. J Am Coll Cardiol 2002;39:241-6.

6. Geske JB, McKie PM, Ommen SR, et al. B-type natriuretic peptide and survival in hypertrophic cardiomyopathy. J Am Coll Cardiol 2013;61:2456-60.

7. Ogino K, Ogura K, Kinugawa T, et al. Neurohumoral profiles in patients with hypertrophic cardiomyopathy: differences to hypertensive left ventricular hypertrophy. Circ J 2004;68:444-50.

8. Pieroni M, Bellocci F, Sanna T, et al. Increased brain natriuretic peptide secretion is a marker of disease progression in nonobstructive hypertrophic cardiomyopathy. J Card Fail 2007;13:380-8.

9. Arteaga E, Araujo AQ, Buck P, et al. Plasma amino-terminal pro-B-type natriuretic peptide quantification in hypertrophic cardiomyopathy. Am Heart J 2005;150:1228-32.

10. Faber L, Welge D, Fassbender D, et al. One-year follow-up of percutaneous septal ablation for symptomatic hypertrophic obstructive cardiomyopathy in 312 patients: predictors of hemodynamic and clinical response. Clin Res Cardiol 2007;96:864-73.

11. Maekawa Y, Jinzaki M, Anzai A, et al. Successful second attempt multidetector computed tomography-guided percutaneous transluminal septal myocardial ablation for an octogenarian with hypertrophic obstructive cardiomyopathy. Int J Cardiol 2014;176:e13 1-e132.

12. Maekawa $Y$, Jinzaki M, Anzai A, et al. Utility of the reverse wire technique in multidetector computed tomography-guided percutaneous transluminal septal myocardial ablation. Int J Cardiol 2014;173:e33-e34.

13. Jensen MK, Almaas VM, Jacobsson L, et al. Long-term outcome of percutaneous transluminal septal myocardial ablation in hypertrophic obstructive cardiomyopathy: a Scandinavian multicenter study. Circ Cardiovasc Interv 2011;4:256-65.

14. Januzzi JL, Troughton R. Are serial BNP measurements useful in heart failure management? Serial natriuretic peptide measurements are useful in heart failure management. Circulation 2013;127:500-8.

15. Masson S, Latini R, Anand IS, et al. Prognostic value of changes in $\mathrm{N}$-terminal pro-brain natriuretic peptide in Val-HeFT (Valsartan Heart Failure Trial). J Am Coll Cardiol 2008;52:997-1003.

16. Maekawa $\mathrm{Y}$, Jinzaki M, Tsuruta $\mathrm{H}$, et al. Multidetector computed tomography-guided percutaneous transluminal septal myocardia ablation in a Noonan syndrome patient with hypertrophic obstructive cardiomyopathy. Int J Cardiol 2014;172:e79-e81.

17. Spertus JA, Jones PG. Development and Validation of a Short Version of the Kansas City Cardiomyopathy Questionnaire. Circ Cardiovasc Qual Outcomes 2015;8:469-76.

18. Green CP, Porter CB, Bresnahan DR, et al. Development and evaluation of the Kansas City Cardiomyopathy Questionnaire: a new health status measure for heart failure. J Am Coll Cardiol 2000;35:1245-55. 
19. Flynn KE, Piña IL, Whellan DJ, et al. Effects of exercise training on health status in patients with chronic heart failure: HF-ACTION randomized controlled trial. JAMA 2009;301:1451-9.

20. Rogers JG, Aaronson KD, Boyle AJ, et al. Continuous flow left ventricular assist device improves functional capacity and quality of life of advanced heart failure patients. J Am Coll Cardiol 2010;55:1826-34.

21. Heidenreich PA, Spertus JA, Jones PG, et al. Health status identifies heart failure outpatients at risk for hospitalization or death. J Am Coll Cardiol 2006;47:752-6.

22. Sorajja P, Ommen SR, Holmes DR, et al. Survival after alcohol septal ablation for obstructive hypertrophic cardiomyopathy. Circulation 2012;126:2374-80.

23. Veselka J, Krejčí J, Tomašov P, et al. Long-term survival after alcohol septal ablation for hypertrophic obstructive cardiomyopathy: a comparison with general population. Eur Heart $J$ 2014;35:2040-5.

24. Pascual-Figal DA, Domingo M, Casas $\mathrm{T}$, et al. Usefulness of clinical and NT-proBNP monitoring for prognostic guidance in destabilized heart failure outpatients. Eur Heart J 2008;29:1011-8.

25. Januzzi JL, Rehman SU, Mohammed AA, et al. Use of aminoterminal pro-B-type natriuretic peptide to guide outpatient therapy of patients with chronic left ventricular systolic dysfunction. J Am Coll Cardiol 2011;58:1881-9.

26. Rigopoulos AG, Seggewiss H. A decade of percutaneous septal ablation in hypertrophic cardiomyopathy. Circ J 2011;75:28-37.

27. Spertus J, Peterson E, Conard MW, et al. Monitoring clinical changes in patients with heart failure: a comparison of methods. Am Heart $J$ 2005;150:707-15.

28. Reynolds MR, Magnuson EA, Lei Y, et al. Health-related quality of life after transcatheter aortic valve replacement in inoperable patients with severe aortic stenosis. Circulation 2011;124:1964-72.

29. Ball W, Ivanov J, Rakowski H, et al. Long-term survival in patients with resting obstructive hypertrophic cardiomyopathy comparison of conservative versus invasive treatment. J Am Coll Cardiol 2011;58:2313-21.

30. Veselka J, Jensen MK, Liebregts M, et al. Long-term clinical outcome after alcohol septal ablation for obstructive hypertrophic cardiomyopathy: results from the Euro-ASA registry. Eur Heart $J$ 2016;37:1517-23.

31. Sorajja P, Binder J, Nishimura RA, et al. Predictors of an optimal clinical outcome with alcohol septal ablation for obstructive hypertrophic cardiomyopathy. Catheter Cardiovasc Interv 2013;81:E58-E67. 